\title{
The effect of a subsidiary task on iconic memory
}

\author{
SIU L. CHOW and BENNET B. MURDOCK, JR. \\ University of Toronto, Toronto, Canada MSS $1 A 1$
}

\begin{abstract}
Using a subsidiary task technique, Doost and Turvey (1971) concluded that iconic memory was independent of the central processing system. However, they did not control the timing between the short-term memory and the iconic-memory tasks in their first experiment and they used a rather long stimulus duration in their second experiment. These procedural difficulties were rectified here in Experiments I and II. It was found that memory load reduced partial report at all interstimulus intervals and there was no interaction. The results of Experiment I were replicated with auditory presentation in Experiment III, ruling out a masking interpretation. Experiment IV ruled out an interpretation in terms of rehearsal or response competition. It was concluded that iconic memory, like short-term memory, is dependent on the central processing system in the sense that it will suffer in a subsidiary-task situation. The locus of the interference effect appears to be in the encoding stage.
\end{abstract}

The concept of iconic memory, a very short-term transient but large-capacity visual store, plays an important part in models of human information processing (e.g., Atkinson \& Shiffrin, 1968; Haber, 1970). Visually presented verbal material is assumed to be held temporarily in iconic memory before any further processing can be carried out.

The need to postulate an "iconic" store, as distinct from a short-term store (STS), is based primarily on Sperling's (1960) partial report findings; see, e.g., Neisser (1967). The typical findings are that (1) the number of letters available at very short interstimulus intervals (ISI) (e.g., $100 \mathrm{msec}$ ) is considerably greater than the number of letters that can be recalled when given the typical memory span task; (2) this superiority of partial report over whole report declines systematically with increases in ISI until the asymptote (memory span) is reached; and (3) partial report is indistinguishable from whole report at asymptote.

By comparing the properties of iconic and short-term stores we have leamed much about the capacity, effective duration, and nature of iconic memory. For example, the iconic store has a greater capacity then STS (Sperling, 1960; von Wright, 1968) and iconic information decays more rapidly then information in STS. Our present concern is with apparently unlimited capacity of the iconic store. The capacity of STS is limited by the central processor, and evidence can be obtained by a subsidiary-task technique (Broadbent \& Heron, 1962; Murdock, 1965). Does the apparently unlimited capacity of the iconic store mean that the iconic store is not subject to the limitations of the central processor?

This research was supported by Grants APA 146 from the National Research Council of Canada and OMHF 164 from the Ontario Mental Health Foundation. The senior author held a postgraduate fellowship from the Nationa Research Council of Canada. Requests for reprints should be sent to Bennet B. Murdock, Jr., Department of Psychology, University of Toronto, Toronto, Ontario. Canada M5S 1 A1.

Thanks are due to Khalid El-Ayat and Howard Kaplan, who gave valuable assistance in the writing of the computer programs for these experiments.
Recently, Turvey (Turvey, 1966; Doost \& Turvey, 1971) made the first systematic attempt to study this problem. Doost and Turvey (1971) argued that, if the iconic store were a "peripheral" store outside the central processor, performance utilizing the iconic store would not be affected by a concurrent task which utilized the short-term memory store. They entertained two alternatives to their null hypothesis. Performing on a short-term memory task would take up some central processing capacity in the sense that a concurrent task would either suffer or interfere with the short-term memory. By the same token, if performance utilizing iconic information required some central processing capacity, a concurrent short-term memory task would suffer or would bring about "...a lower level of recall and perhaps a faster decay rate of iconic information" (p. 269).

Doost and Turvey compared the partial-report performance of their subjects under "memory load" and "no memory load" conditions and found no significant difference. Failing to reject their null hypothesis, they concluded that iconic memory was not subject to limitations due to the central processor. However, we have reservations about their finding because of one aspect of their procedure. Under the "memory load" condition, the $3 \times 5$ display ( 3 rows of 5 letters each, subsequently called the "partial-report display") used in the partial-report task was preceded by a trigram. The delay between the trigram and the partial-report display was controlled by the subject. The average delay from the onset of the partial-report display to the offset of the trigram was $3 \mathrm{sec}$. Under such circumstances, it is difficult to tell to what extent the trigram had been processed before the subject initiated the partial-report display. For example, the subject could easily have overlearned the trigram before initiating the partial-report display. Moreover, subjects were instructed to repeat aloud the trigram. This rehearsal might inadvertently have provided subjects with helpful echoic cues. 
Our reservation about the Doost and Turvey procedure suggested that their first experiment should be repeated with a controlled interval between the short-term and the iconic-memory tasks and with no instruction to verbalize.

\section{EXPERIMENT I}

\section{Method}

Subjects. Six female paid volunteers were recruited from undergraduate students at the University of Toronto. They were naive as to the purpose of the experiment.

Apparatus. The experiment was programmed and conducted by a PDP-12A computer driving a VR-12 oscilloscope. The type of phosphor used in the oscilloscope was P31, whose green luminosity, according to the manufacturer's specifications, decays within 40 microsec to $10 \%$ of its maximum luminosity at painting offset. The painting was refreshed every $25 \mathrm{msec}$ after the onset of each painting cycle. As a $50-\mathrm{msec}$ duration was intended for the partial-report display, there were 2 refresh cycles for the partial-report display. The pre- and postexposure fields were dark.

Materials. Twenty-three alphanumeric characters were used in the experiment. They were B, C, F, H, J, K, L, M, N, P, R, S, T, $\mathrm{X}, \mathrm{Z}, 2,3,4,5,6,7,8$, and 9 . On any partial-report trial, 15 alphanumeric items were selected without replacement from the 23 items. In tasks where there was a preceding trigram, 3 more items were randomly selected, also without replacement, from the remaining 8 items not used in the partial-report display on that particular trial.

The partial-report display subtended a visual angle of $3 \mathrm{deg}$ $24 \mathrm{~min}$ by $3 \mathrm{deg} 50 \mathrm{~min}$. The trigram occupied the three central locations of the middle row of the partial-report display. Each alphanumeric character was constructed from a $4 \times 6$ grid which measured $1 / 4 \times 1 / 4$ in. The upper case was used for alphabetic characters. The probe tones used in the experiment were generated by a Hewlett-Packard 3300A function generator which was also controlled by the computer.

Experimental Tasks. Task 1, the "no memory load" task condition, was a partial-report task which served as the control task. On each trial, the subject was shown the partial report ( $3 \times 5)$ display for $50 \mathrm{msec}$. At various delays after the offset of the display, one of three possible probe tones was given. The subject was to recall only the row probed by the tone; the tones were high $(708 \mathrm{~Hz})$, medium $(382 \mathrm{~Hz})$, and low $(218 \mathrm{~Hz})$ for the upper, middle, and the lower row, respectively. In Task 2 (the "Is B in trigram?" condition) subject was shown a trigram for $500 \mathrm{msec}$ at the start of a trial. After various delays, Task 1 would be given. The subjects were told to perform on the partial-report task and then report whether or not the trigram contained the letter "B." In Task 3 (the "remember trigram" condition), the sequence of events was like that of Task 2. Here, however, subject was told to perform on the partial-report task and then recall the trigram.

Design. The design was a split-plot factorial design. Order of task (amount of memory load) administration was the between-groups variable. Intertask interval (ITI), interstimulus interval (ISI), and type of task (amount of memory load) were within-subjects variables. The 5 ITIs were $0.525,1.0,1.5,2.0$, and $3.0 \mathrm{sec}$. The 5 ISIs were $25,125,250,500$, and $1,000 \mathrm{msec}$.

Procedure. Each subject participated in 6 sessions. The first 3 were training sessions and the last 3 were test sessions. Each subject was trained on Tasks 1,2 , and 3 on Days 1, 2, and 3, respectively. Three subjects were tested on Tasks 1,2 , and 3 on Days 4,5 , and 6 while the other three subjects were tested in the reverse order. Thus, the mean position per task was perfectly balanced.

In each session, there were 220 trials, the first 20 of which were practice trials and not analyzed. The 200 test trials were divided into 10 blocks of 20 trials each. Within each block, the 3 rows were tested almost equally frequently $(7,7,6)$. The less frequently tested row was randomly determined for each block. There were 25 ISI by ITI combinations, so each was tested 8 times, randomly distributed, in the 200 test trials.

The sequence of events which constituted a trial was as follows. All trials began with a warning beep. In cases where the trigram was not shown (i. e., the "no memory load" condition), a fixation point was shown for $500 \mathrm{msec}$ whose onset was half a second after the end of the warning beep. The partial-report display was then presented for $50 \mathrm{msec}$ half a second after the offset of the fixation point. A + sign was used as the fixation point. In cases where there was a trigram preceding the partial-report display, the trigram was given $1 / 2$ sec after the offset of the fixation point. At the moment the chosen ITI expired, a second fixation point was given for $500 \mathrm{msec}$. The partial-report display was then given $1 / 2 \sec$ after the end of the second fixation.

The subject was allowed $5 \mathrm{sec}$ to respond. The break between blocks was $16 \mathrm{sec}$. The whole session was paced by the experimenter. The room was dark except for a 25 -W lamp.

\section{Results}

Items reported were scored as correct only if they were reported in their correct positions. Figure 1 shows the mean number of items available (using the Sperling scoring system) averaged across subjects for each of the 5 ISIs for Tasks 1, 2, and 3.

As can be seen, partial-report performance declined systematically with increases in ISI. Memory load

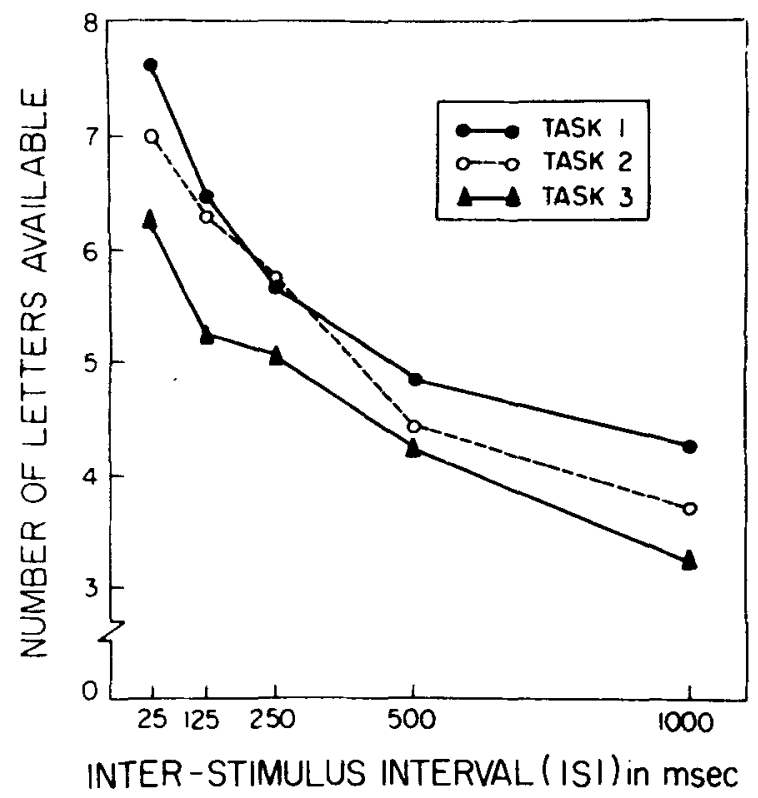

Figure 1. Number of letters available as a function of ISI and task (Experiment I). Task 1 was the standard partial-report task; Task 2 was to recall whether the preceding trigram contained a ' $B$ ' after the standard partial-report task; Task 3 was to recall the trigram after the standard partial-report task. 


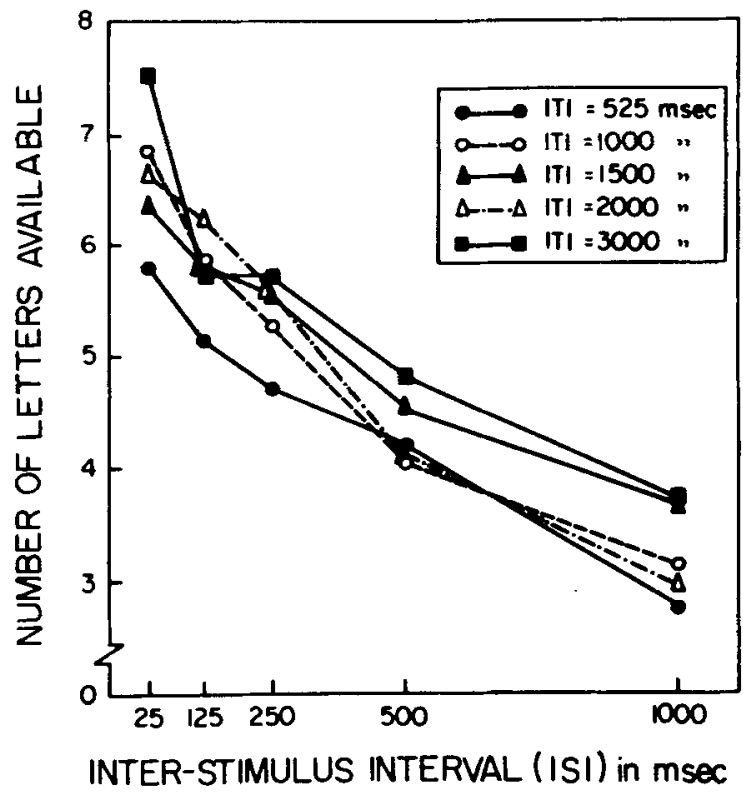

Figure 2. Number of letters available as a function of ISI and ITI for Traks 2 and 3 (Experiment I).

reduced partial-report performance by lowering the overall performance level without changing the slope of the partial-report function. Analysis of variance showed that both the ISI and the task effects were significant; for ISI, $[F(4 / 128)=87.5, p<0.05 ;$ for task, $F(2 / 8)=23.86, p<0.05]$. The estimates of error variance for both ISI and task were 0.52 . Other effects were insignificant.

Figure 2 gives the mean number of items available averaged across subjects and Tasks 2 and 3 for each ISI and ITI value. As can be seen, for any ITI, partial-report performance also declined systematically with increase in ISI. Figure 3 shows the partial-report performance increased monotonically with increases in ITI. Analysis of variance showed that the ITI effect was significant $[F(4 / 80)=4.14, p<0.05]$. The estimate of error variance of ITI was 0.57 . There was neither an ITI by Task nor an ITI by Task by ISI interaction.

When required to recall whether the trigram contained a "B" (Task 2), the mean proportion of correct responses was 0.97 . When required to recall the trigram items (Task 3), the average number of trigram items recalled was 2.7 out of 3 . Neither the accuracy of the detection of " $B$ " nor the recall of the trigram varied with ITI or with the ISI used in the partial-report task.

Errors committed by the subjects in their partial report were also examined. Apart from omissions (which were the majority), subjects sometimes recalled the correct items in some wrong positions. Such transposition errors occurred equally frequently under the various memory-load conditions. What is interesting is that there were frequent visual confusion errors (e.g., a " $G$ " wrongly recalled as a " 6 "); there were practically no acoustic confusion errors.
Though the three probe tones were chosen from a relatively narrow range, there were only a few cases in which one subject had them confused. There was not any intertask confusion error in the sense that subjects did not give a short-term memory item in their partial report, and they did not give a partial-report item in their short-term memory task.

\section{Discussion}

These data suggest that Doost and Turvey accepted their null hypothesis incorrectly. Contrary to their contention, it was found here that the short-term memory load affected performance utilizing the iconic store. If the intercept of the partial report function represents the capacity of the iconic store, our data suggest that memory load reduces the capacity of the iconic store without affecting the rate of decay of iconic information.

Experiment I differed from Doost and Turvey's first experiment in that the ITI was controlled here. The observed task effect suggested that the lack of control of the ITI variable might be responsible for Doost and Turvey's failure to reject their null hypothesis. Consistent with such a contention is the following observation. When required to recall the trigram, the mean number of items available was 5.18 at ITI $=3 \mathrm{sec}$. The mean number of items available when there was no memory load was 5.82. That is to say, an ITI of $3 \mathrm{sec}$ was still insufficient to counter the detrimental effect of memory load on iconic memory. However, the absence of an ITI by Task interaction effect renders the role of the ITI variable ambiguous. But the near perfect recall of short-term memory items suggests that the subsidiary

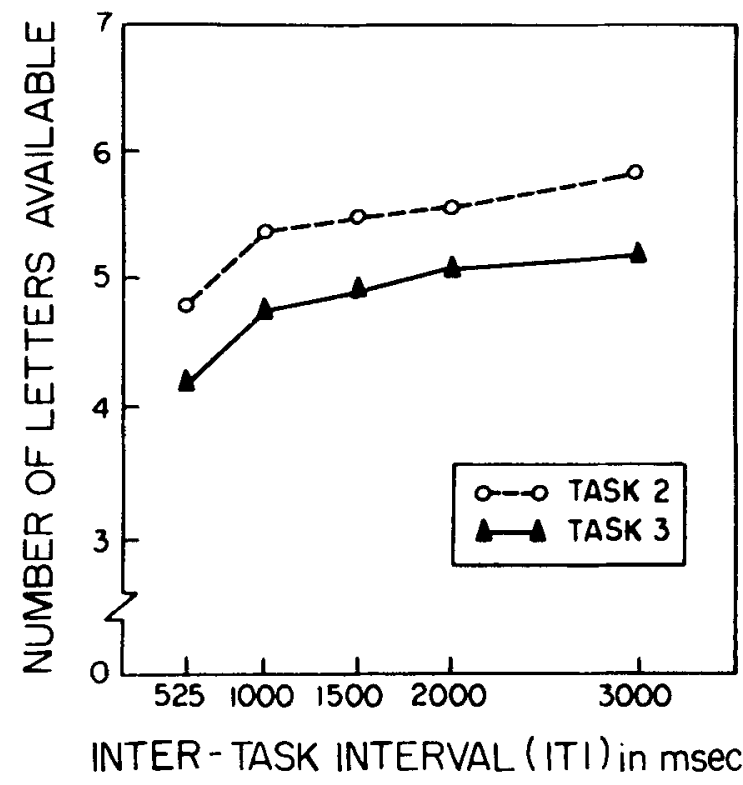

Figure 3. Number of letters available as a function of ITI and task for Tasks 2 and 3 (Experiment I). 
memory task might simply be too easy for the ITI by Task interaction effect to show.

The significant task effect probably was not due to forward masking from the visual presentation of the trigram. If there had been any forward masking effect, such an effect would apply equally to Tasks 2 and 3 . However, the partial-report performance was worse, especially at short ISIs, when subjects had to remember the trigram items than when they only had to detect a "B."

\section{EXPERIMENT II}

It could be that the STM task in Experiment I reduced the subject's partial report performance by distracting the subject's attention in a way analogous to distraction by extraneous noise while engaged in reading. If that were the case, the results would not prove that iconic memory is dependent on the central processing system, and Doost and Turvey's original contention might still be correct. Alternatively, the STM task might have distracted the subject's attention in a way analogous to the effect of counting backward in a typical Brown-Peterson paradigm. That is, the distraction might be due to the fact that the central processing capacity was limited. Such an alternative would be more damaging to Doost and Turvey's contention.

The second experiment reported by Doost and Turvey suggested a paradigm for testing these two alternatives. They again compared the partial-report performance under three conditions. The control condition was the standard partial-report condition. In the two experimental conditions, an auditory item was presented concurrently with the partial-report display. The subject either had to ignore the auditory item or decide immediately whether it was a consonant or a vowel before performing on the partial-report task. To the extent that central processing capacity was required in utilizing iconic information, either the concurrent or the partial-report task should suffer. Doost and Turvey did not find any significant difference in the partial-report performance under these three conditions, nor was the concurrent classification task affected by the partial-report task. They concluded that iconic memory did not take up any portion of the limited central processing capacity. That is to say, iconic information was independent of the demands on the central processor.

Unfortunately, we cannot accept Doost and Turvey's conclusion nor can we use their observation to rule out the "peripheral distraction" explanation. The reason is that the duration of their partial-report display was too long $(180 \mathrm{msec})$. Such a time interval exceeds the normal values typically associated with iconic memory. Experiment II was carried out to determine if this distraction explanation could account for our data in
Experiment I, to reexamine the claim that a concurrent auditory classification task would not adversely affect partial-report performance, and to explore the question of whether the rate of decay of iconic information could be affected by an auditory stimulus presented during the ISI.

Subjects. The six subjects of Experiment I were recruited again. They had not been informed about the purpose of Experiment I at its conclusion, nor were they told about the purpose of Experiment II.

Material. The alphanumeric material and the probe times used were those used in Experiment I.

Apparatus. The apparatus used was identical to that of Experiment I.

Experimental Tasks. Task 1 (the "no concurrent task" condition) was the control task which was a standard partial-report task. (See Task 1 of Experiment I.) Task 2 will be called the "immediate response to tone" task. The onset of a trial was signaled by a $50-\mathrm{msec} 502-\mathrm{Hz}$ tone (called the "warning tone"). Either concurrently with the partial-report display, or in the middle of the ISI, a $502-\mathrm{Hz}$ test tone of variable duration (i.e., 25,50 , or $100 \mathrm{msec}$ ) was presented. (When the ISI was $125 \mathrm{msec}$ on a particular trial, the test tone was presented immediately at the offset of the partial-report display). The probe tone pertinent to the partial-report task was presented after a chosen delay. Upon hearing the test tone, the subject had to decide immediately whether the test tone was shorter than, as long as, or longer than the warning tone by pressing the appropriate key. Then he recalled the probed row of letters.

Task 3 will be called the "delayed response to tone" task. The sequence of events which constituted a trial was exactly like that of Task 2 . The subject had to perform on the partial-report task before writing down his response to the tone-duration discrimination task. Task 4 will be called the "ignore tone" task. The sequence of events was like that of Task 2, but the subject was told to ignore the test tone. He was required to perform on the partial-report task only.

Design. The design was a split-plot factorial design. Order of task administration was the between-groups variable. Interstimulus interval (ISI) and type of task were within-subjects variables. The 5 ISIs used were 125,250 , 500,750 , and $1,000 \mathrm{msec}$.

Procedure. Each subject participated in 9 sessions. The first two sessions were training sessions. They were trained on Tasks 2 and 3 on Days 1 and 2, respectively. The subjects were trained extensively on the tone-duration discrimination task with a $502-\mathrm{Hz}$ tone in Day 1 as well. They were first presented tones on 25,50 , and $100 \mathrm{msec}$ duration. They were then presented pairs of tones, the first tone of each pair always being a $50-\mathrm{msec}$ tone. The second tone might be a $25-$, a $50-$, or a $100-\mathrm{msec}$ tone, and they had to indicate which. Their discrimination performance was assessed every 15 trials. They had to reach errorless performance before they were given training on the experimental task. Such a training procedure was repeated at the onset of every subsequent session. 
The six subjects were split into 2 groups of 3 for testing purposes. Group 1 received Task 1 on Day 3, Task 2 on Days 4 and 5, Task 3 on Days 6 and 7, and Task 4 on Days 8 and 9 . The other group of subjects received the reverse order. When a task (e.g., Task 2) was tested on 2 occasions, one day was devoted to the condition where the test tone was presented concurrently with the partial-report display. The other day was devoted to the condition when the test tone was presented during the ISI. In other aspects, the procedure was like that of Experiment $I$.

\section{Results}

Only items recalled in their correct positions were scored as correct. Preliminary analysis showed that it did not matter whether the test tone was presented concurrently with the partial-report display or during the ISI. The crucial factor was whether an immediate response to the test tone was required. Consequently, for Tasks 2,3 , and 4 , the data collected on the two days devoted to the same task were collapsed. Figure 4 shows the mean number of items available averaged across subjects for each of the five ISIs for Tasks 1, 2, 3, and 4.

It can be seen from Figure 4 that the partial-report performance was reduced if an immediate response to the test tone was required. As in Experiment $I$, this subsidiary task reduced partial-report performance by lowering the overall performance level without changing the slope of the ISI function. Analysis of variance showed that both the ISI and the task effects were significant; for ISI $[F(14 / 38)=35.7, p<0.05]$, for task, $[F(3 / 38)=21.30, p<0.05]$. The estimates of error variance for both ISI and task was 0.31 . There was no ISI by Task interaction.

A posteriori tests of differences among means revealed that the "ignore tone" task (Task 4) gave significantly better partial-report performance than did the "immediate response to tone" task (Task 2); Tukey's $q(0.05,12)=4.63$. Other a posteriori tests did not show any significant effects. The proportion of correct tone-duration discriminations was 0.75 for the "immediate response to tone" task and 0.66 for the "delayed response to tone" task.

\section{Discussion}

Our present findings can best be summarized as follows. The partial-report performance was not reduced by the mere presence of a tone, either concurrently with the partial-report display or during the ISI, if the subject could ignore it or did not have to make an immediate response to it. This peripheral event did not distract the subject's attention from the partial-report display. Such an observation can be used as an indirect refutation of the possibility that STM load distracted the subject's attention (in a peripheral sense) in Experiment I.

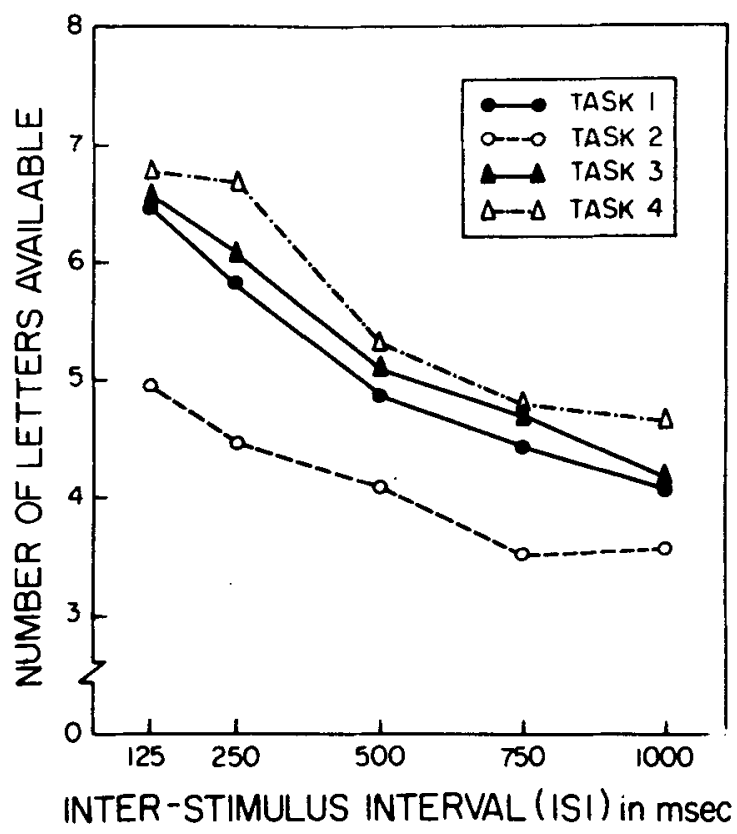

Figure 4. Number of letters available as a function of ISI and task (Experiment II). Task 1 was the standard partial-report task; Task 2 was the "immediate response to tone" task; Task 3 was the "delayed response to tone" task; Task 4 was the "ignore tone" task.

The partial-report performance was reduced when subject had to make the tone-duration judgment immediately. This observation is contrary to Doost and Turvey's contention that partial-report performance did not impose any demand on the central processing system. Their contention is further weakened by our observation that, while the partial-report performance did not suffer when the tone-duration response was delayed, the tone-duration judgment itself suffered. That is to say, there was an inverse relationship between the two concurrent tasks.

It should be noted that the partial-report performance was stabilized before data were collected. It should also be pointed out that the presence of the test tone facilitated the decoding of the subsequent probe tone. There was no test tone in the standard partial-report task (Task 1); hence, it was more difficult to decode the probe tone in Task 1 than in other tasks. Consequently, the "ignore tone" task (Task 4) where the test tone was presented but ignored was a more satisfactory control task. Our conclusion is not weakened by the fact that a posteriori tests did not reveal any significant difference between the standard partial-report and the "immediate response to tone" tasks. 


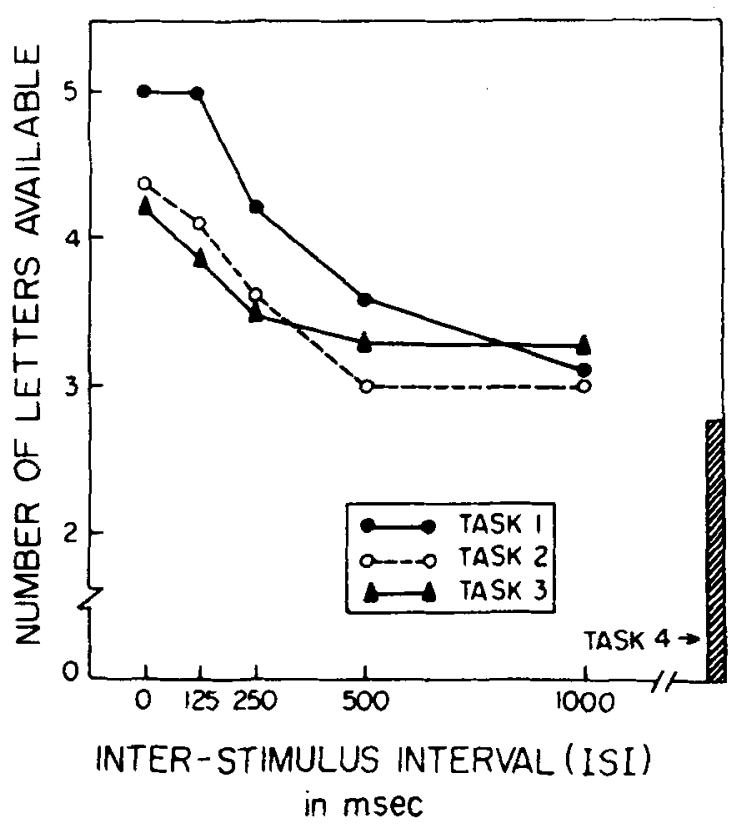

Figure 5. Number of letters available as a function of ISI and task (Experiment III). Task 1 was the standard partial-report task; Task 2 was to recall whether the preceding trigram contained a ' $B$ ' after the standard partial-report task; Task 3 was to recall the trigram after the standard partialreport task; Task 4 was the whole-report task.

\section{EXPERIMENT III}

Following Doost and Turvey, we presented our STM items visually in Experiment 1 . Would similar results be obtained if the trigram were presented auditorily?

In Experiment I, the number of items available when given the standard partial-report task and probed at $I S I=25 \mathrm{msec}$ was 7.61 , and it declined with increases in ISI. It was assumed that iconic memory was demonstrated in the sense that the classic decay function of Sperling (1960) was obtained. However, crucial to such a conclusion is that partial-report at short ISI should be superior to whole report and that this superiority should decline with increases in ISI. Neither of these two observations was made in Experiments I or II because the whole-report task was omitted. Consequently, it was decided that the whole-report task should be included in Experiment III.

\section{Method}

Subjects. Six ( 5 female and 1 male) paid volunteers were recruited from the research assistants and graduate students at the University of Toronto. They were naive as to the purpose of the experiment.

Apparatus. Whenever applicable, auditory items were presented via earphones with a Sony TC-200 tape recorder. Synchronization between the tape recorder and the computer was achieved by lising a Uher diapilot.
A female speaker read three alphanumeric items at a steady rate within half a second. As soon as she finished the last item in a string, a mark was made on the tape with the diapilot. When the tape was played back, the diapilot mark caused the program to present, in succession, the fixation point, the partial-report display, and the probe tone.

Other aspects of the apparatus used were identical to those of Experiment 1 .

Material. The alphanumeric characters and the probe tones used were identical to those used in Experiment I.

Experimental Tasks. Task 1 (the "no memory load" condition) was the contrcl task which was a standard partial-report task. (See Task 1 of Experiment I.) For Task 2 (the "Is B in trigram?" condition), at the onset of a trial the subject heard a trigram whose presentation duration was approximately $0.5 \mathrm{sec}$. At various delays (ITI), Task 1 would be given. The subject was told to perform on the partial-report task and then recall whether the trigram contained a "B." For Task 3 (the "remember trigram" condition) the sequence of events was like that of Task 2, but the subject was told to perform on the partial-report task and then recall the actual trigram items. Task 4 was the whole-report task. On each trial, the subiect was presented three tows of 5 items for $50 \mathrm{msec}$. He was told to recall as many items as he could in their correct positions as soon as the stimulus display was withdrawn. There was no probe tone for Task 4 .

Design. The design was a split-plot factorial design. The order of task administration was the between-groups variable. Intertask intervai (ITI), interstimulus interval (ISI) and type of task were within-subjects variables. The 5 ITIs were $0.525,1.0,1.5,2.0$, and $3.0 \mathrm{sec}$. The 5 ISIs were 0 , $125,250,500$, and $1,000 \mathrm{msec}$.

Procedure. Each subject participated in 7 sessions. The first 3 sessions were training sessions; the last 4 sessions were testing sessions. The order of training was Tasks 1, 2, and 3 on Days 1, 2, and 3, respectively, for all subjects.

The 6 subjects were split into 2 groups for testing purposes. One group of 3 subjects received Tasks 1, 2, and 3 on Days 4, 5, and 6, respectively. The other group of subjects received the reverse order. All subjects were given Task 4 on Day 7. For the whole-report task, subjects were given $3 \times 5$ grids which corresponded to the $3 \times 5$ stimulus display. Other aspects of the procedure were the same as Experiment I.

\section{Results}

Only items recalled in their correct positions were scored as correct. Figure 5 shows the mean number of items available averaged across subjects for each of the 5 ISIs for Tasks 1, 2, and 3. Also included in Figure 5 is the mean number of items (2.75) recalled when given the whole-report task. As can be seen, the partial-report performance declined systematically with increases in ISI. At ISI $=0$, the number of items available was 5.08 , nearly twice as many as the number of items recalled when given the whole-report task. Such a superiority of the partial-report task over the whole-report task declined systematically with increases in ISI.

The partial-report performance was reduced when subject had to engage in a STM task. Analysis of 
variance showed that both the ISI and the task effects were significant; for ISI $[F(4 / 128)=18.63$, $\mathrm{p}<0.05]$; for task, $[\mathrm{F}(2 / 128)=16.43, \mathrm{p}<0.05]$. The estimates of error variance for both ISI and Task was 0.54. Other effects were insignificant.

As in Experiment $I$, the ITI variable was applicable to Tasks 2 and 3 only. There was no ITI effect. The mean number of items available was plotted against each ITI value in Figure 6. As can be seen, the partial report performance was essentially flat for Task 2 . There is some indication that the partial-report performance increased with an increase in ITI when given Task 3.

When required to remember the " $B$ "-detection response, the mean proportion of correct responses was 0.99 . When required to recall the trigram items, the mean number of trigram items recalled was 2.82 out of 3 . In neither case did accuracy vary with ITI or with ISI used in the partial-report task.

\section{Discussion}

With the inclusion of the whole-report condition, this experiment clearly established that we are dealing with iconic memory as measured by Sperling's partial-report task. The absolute performance level of our subjects' partial report was admittedly low, but so was their. whole report. The main points are that partial report was superior to whole report and that this superiority decreased systematically with increases in ISI.

Unlike Experiment 1 , auditory presentation of memory items was used in this experiment. If the observed reduction in partial report in Experiment I was due to some sort of masking, one would not expect any reduction in partial report in this experiment. Our observation to the contrary would seem to rule out a masking interpretation of our data.

The results of the present experiment differed from those of Experiment I in several respects. First, there was a significant ITI effect in Experiment I when the memory items were presented visually. Partial report increased systematically with increases in ITI. Here there was no ITI effect when auditory presentation was used. This discrepancy between Experiments I and III is presumably due to the differing modes of presentation (visual or auditory) used in the STM task.

The second aspect in which Experiments I and III differed was the partial-report performance when the subjects had to remember whether or not the trigram contained a "B" (labeled Task 2 in both experiments). It was more like the performance level of the standard partial-report task in Experiment I, but it was more like the performance level of the task where the subject had to remember the trigrams in Experiment III. Some subjects in Experiment I mentioned that to remember whether or not there was a " $B$ " in the trigram was easy because they could make the decision in the presence of the trigram and then remember their binary decision. But some subjects in Experiment III reported that they could not help remembering the whole trigram even though they were told only to detect a "B." It seemed as though Tasks 2 and 3 imposed different amounts of memory load in Experiment I but the same amount in Experiment III. One is tempted to suggest that the usefulness of iconic information is inversely related to STM load.

\section{EXPERIMENT IV}

Following Doost and Turvey's paradigm, we required our subjects to perform first on the partial-report task and then on the short-term memory task in Experiments I and III. One current view is that iconic information has to be transferred into short-term memory before any overt responses can be made (see, for example, Haber and Hersenson, 1973). In terms of this view, the observed reduction in partial-report performance might not reflect a reduction in iconic memory.

One interpretation, then, of our data might be that, as short-term memory was filled with memory items, fewer iconic items could be transferred into short-term memory. Consequently, the drop in partial report might only reflect fewer items being transferred into short-term memory. An alternate interpretation is that, when subjects were required to perform on both the iconic and the short-term memory tasks, it was simply more difficult to select the correct responses for the partial-report task.

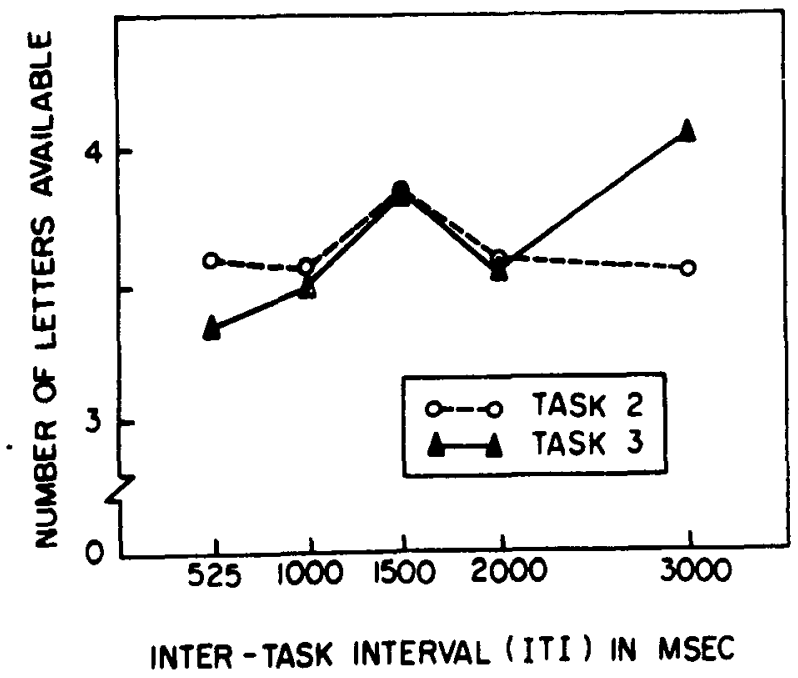

Figure 6. Number of letters available as a function of ITI and task for Tasks 2 and 3 (Experiment III). 
In view of these possibilities, Experiment I was repeated except that, on any trial, the subjects had only to perform on either the partial-report task or the short-term memory task, but never both. The cue as to which task to perform was given after both the short-term memory items and the partial report display had been presented. If either of the above alternatives were correct, one would not expect a reduction in the subjects' partial-report performance.

In earlier experiments, we have the mean position per task balanced instead of the usual counterbalancing procedure. In order to eliminate any possible confounding between the order effect and the task effect, all experimental manipulations were tested in the same session in a completely random manner.

\section{Method}

Subjects. Four ( 3 female and 1 male) paid volunteers were recruited from the Arts and Science Faculty of the University of Toronto. They were naive as to the purpose of the experiment.

Apparatus. The apparatus used was identical to that of Experiment $\mathrm{I}$.

Material. In addition to those 23 alphanumeric characters used in Experiment I, D, G, V, and $\mathrm{W}$ were included in the ensemble. Their inclusion in this experiment was made possible because a new and more satisfactory set of graphics had been developed. Each alphanumeric character was constructed from a $24 \times 24$ grid. The upper case was used for alphabetic characters.

The partial-report display subtended a visual angle of $5 \mathrm{deg} 24 \mathrm{~min}$ by $3 \mathrm{deg} 48 \mathrm{~min}$. The trigram occupied the three central locations of the middle row of the partial-report display. The probe tones used were the same as those used in Experiment I.

Procedure. There were 180 trials in a session: 90 partial-report trials, 60 short-term memory trials, 20 whole-report trials, and 10 warmup trials. The 10 warmup trials were chosen randomly from among the 30 treatment combinations. These 180 trials were presented in a random fashion.

Each trial began with a warning tone (or 3 short warning tones if it was a whole-report trial). Simultaneously with the onset of the warning tone (or tones), a message would appear on the upmost position of the screen. The message notified the subject what type of memory load would be given for that trial. When the subject was ready, the subject pressed a switch to initiate the presentation of the memory items. From this point on, the sequence of events was entirely paced by the program.

First, a fixation point (a + sign) was presented for $500 \mathrm{msec}$. Half a second elapsed before the memory items were presented for $500 \mathrm{msec}$. (In cases where there was no memory load, $3 \%$ signs were presented in lieu of alphanumeric items.) There was an intertask interval between the end of the memory items and the onset of a second fixation point. The fixation was again on for $500 \mathrm{msec}$. There was a blank interval of half a second at the end of the fixation point. Then the partial-report display was presented for $50 \mathrm{msec}$. Either a beep would be presented at the end of the partial-report display or 1 of 3 equally probable tones would be given at a prescribed delay. If the subject heard a beep, the subject was to recall the memory items only. (In cases where the subject saw only $3 \%$ signs, the subject was to draw only $1 \%$ sign.) If, on the other hand, the subject heard a tone, he was to recall the row of the partial-report display signaled by that tone.

In cases where the subject heard 3 warning tones, a message would signify that it was a whole-report trial. When the subject pressed the switch, a fixation point would be given for $500 \mathrm{msec}$. After a delay of half a second, the partial-report display would be given for $50 \mathrm{msec}$. The subject was told to recall as many items from the $3 \times 5$ display as he could in their correct positions as soon as he was ready to do so. There was not any probe for the whole-report trials.

The subjects participated in eight 1-h sessions. In the first session, they were trained to discriminate between the three probed tones to a criterion of errorless performance in 15 trials. They then read a flow-diagram describing the sequence of events constituting a trial. The flow-diagram was then explained to the subjects verbally. The various conditions involved in the experiment were then illustrated to the subjects.

The first three days were for practice purposes. Experimental data were collected on Days 4 through 8. The subject's ability to discriminate between the probe tones was monitored before every session. In all cases, they had to have an errorless tone-discrimination performance (in 15 trials) before the session began.

Other aspects of the procedure were like those of Experiment I.

Design. The design was a completely randomized factorial design. The three factors involved were interstimulus interval (ISI), memory load, and task. The five ISIs were $0,125,250,500$, and 1,000 msec. The three memory-load conditions were "no memory load," "Is B in the trigram?," and "Remember trigram." There were two tasks. The subjects either performed on the partial-report task or on the short-term memory task. There were $30(5 \times 3 \times 2)$ treatment conditions, but subjects were tested more often on the partial-report task than on the short-term memory task.

There were 90 partial-report trials in a session. Each one of the 15 ISI by Memory Load treatment combinations was tested 6 times, twice on each one of the 3 rows in the partial-report display. There were 60 short-term memory trials, 20 times for each memory-load condition in a session.

The probe (a beep) which designated the memory task was always given at the immediate offset of the partial-report display. Only one level of inter-task interval (ITI) was used, viz., $750 \mathrm{msec}$.

\section{Results}

Only items recalled in their correct positions were scored as correct. The number of items available at various delays under the three memory load conditions averaged across subjects are shown in Figure 7. The whole-report task is shown by the vertical line (Task 4). As can be seen, partial-report performance was reduced by the subsidiary memory task. The memory load effect was significant $[F(2 / 240)=8, p<0.05]$. The ISI effect was also significant $[F(4 / 240)=32, p<0.05]$. The error estimate was 0.72 in both cases. 
The average number of short-term memory items recalled in their correct positions was 2.92, 2.89, 3.0, and 2.96 (out of 3) for Subjects 1, 2, 3, and 4, respectively. When required to remember whether the trigram contained $a$ ' $B$ ' or not, the mean proportion of correct responses (including correct rejection and correct identification) was $0.96,0.98$, 0.99 , and 0.99 for Subjects 1, 2, 3, and 4, respectively.

As in Experiment I, there were no cases of intertask intrusions. Subjects did not recall any memory items in their partial-report, nor did they give any partial-report items in their recall of memory items. Apart from omissions, subjects often recalled some correct items in wrong positions in their partial report. There were consistent visual confusion errors, but no acoustic confusions.

As in previous experiments, there were only a few cases in which subjects confused the probe tones. There were no cases of confusion between the type of memory task involved when probed to perform on the memory task. For example, when precued that it was a "Remember trigram" condition, subjects did not treat it as an "Is $B$ in the trigram?" condition.

\section{Discussion}

The perceptual effects of the various memory load conditions were held constant in this experiment by having a 3-item string precede the partial-report display. This manipulation provided another refutation of the intramodality interference interpretation of the effect of memory load per se on the efficacy of iconic memory.

Unlike Experiments I and III, memory load in this experiment was relevant only during the interval between the presentation of the memory items and the duration of the partial-report display because the subjects had to do only one task on any given trial. The subjects were presented 3 items (alphanumeric or \% signs) and then 3 rows of 5 items each. They had sufficient time to store them in short-term memory. They had to retain them up to the moment the partial-report display expired. If they heard a beep, they then recalled the alphanumeric items (or whether they contained a "B"). If they did not hear a beep, they could forget the memory items and concentrate on the partial-report task. In terms of current models of information processing, memory load was relevant only up to the stage in which iconic information was extracted from the partial-report display. Memory load was irrelevant in any subsequent stages; e.g., the stage in which iconic information is scanned, or the stage in which overt responses are organized and made.

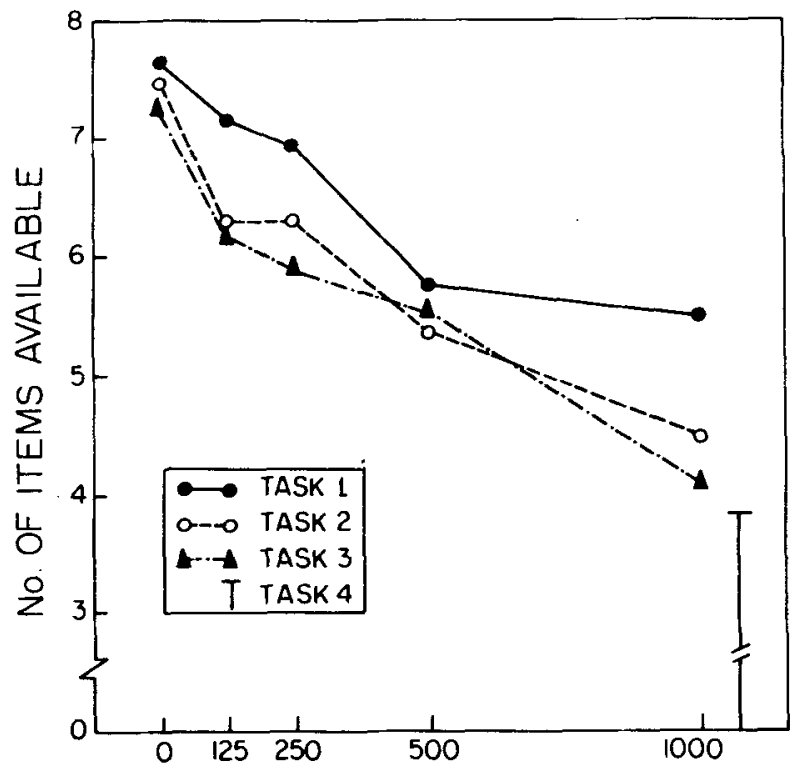

INTERSTIMULUS INTERVAL (ISI) IN MSEC

Figure 7. Number of letters available as a function of ISI and memory load (Experiment IV). Task 1 was the "no memory load" condition; Task 2 was the "Is B in trigram?" condition; Task 3 was the "remember trigram" condition; Task 4 was the whole-report task.

It can be assumed that the time required to clear the short-term memory store is negligible compared to the time the subjects would take to initiate their responses. Given our manipulation, subjects could effectively have a clear short-term memory store when the iconic memory task was required. Given a clear short-term memory store, one would not expect less information being transferred into short-term memory. By the same token, one would not expect any interference due to rehearsal or response competition when the subjects were required to perform the partial-report task if there was not any subsequent memory task to perform. That is to say, in neither account would one expect a reduction in partial report. Our observation to the contrary suggests both of these two interpretations are untenable. More specifically, it can be said that neither the response process nor the limitations due to short-term memory was responsible for the results obtained in this series of experiments.

As in Experiments I and III, there was no ISI by Memory Load interaction effect. That is to say, memory load did not cause iconic information to decay at a faster rate. The retention phase of iconic memory is then excluded as a possible locus of memory load effect. One implication of this observation is that iconic information is not maintained actively. 
Having excluded the retention and the output phases of iconic memory as the possible loci of memory load effect, we can suggest that memory load reduced the efficacy of iconic memory by reducing the amount encoded. It may be the case that the amount of iconic information extracted from the partial-report display was reduced when the subjects could not devote themselves solely to the partial-report display while it was present. Consistent with this contention is the observation that partial report was lower when there was memory load even at the shortest ISI value $(0 \mathrm{msec})$. The implication of this conclusion is that the extraction of iconic information is not as automatic as it is currently considered to be.

\section{GENERAL DISCUSSION}

The most general finding in this series of experiments was that partial-report performance was reduced when there was a concurrent memory load or task. The reduction in partial report took the form of a lower performance level at every delay interval (ISI). Further, there was no interaction between ISI and the experimental manipulations. That is to say, the rate of decay of iconic information was not affected by memory load or a concurrent task. The fact that reduction in partial report occurred even at $\mathrm{ISI}=0 \mathrm{msec}$ was interesting. As will be argued subsequently, these observations suggest that memory load affected the encoding stage of iconic memory. As the capacity of iconic memory at ISI $=0 \mathrm{msec}$ has been treated as an index of the amount perceived at a glance (Sperling, 1960; Haber, 1973), our finding implies that the amount perceived at a glance is reduced if the observer is otherwise engaged.

Let us now consider some possible objections to these conclusions. The first point to note is that the absolute performance level of our subjects was not as high as expected. It might be that the intensity of our oscilloscope display was lower than what could be achieved with a tachistoscope. Another contributing factor to the overall low absolute performance level might have been our choice of probe-tone frequencies. Doost and Turvey used frequencies of 200,600 , and $2,000 \mathrm{~Hz}$ (Set 1); we used frequencies of 218,382 , and $708 \mathrm{~Hz}$ (Set 2). We used Set 2 for experimental convenience, and pretesting showed that they were easily discriminable. Nonetheless, they might be more difficult to discriminate than those used by Doost and Turvey.

It is important, however, to realize that our choice of probe tones does not invalidate our conclusions, nor can it explain the different results obtained by Doost and Turvey and by us. For example, Doost and Turvey did not find any memory load effect in their experiment, but a significant memory load effect was observed here in Experiments I, III, and IV. Even though our subjects might have found it more difficult to decode the probe tones than their counterparts in Doost and Turvey's experiment, such a difficulty should apply equally to all partial-report tasks regardless of whether or not there was any memory load. Our interest was in the relative partial-report performance levels under various memory load conditions. Hence, it would be wrong to suggest that a significant memory load effect was found here in these experiments because a particular set of probe tones had been used.

The observed reduction in the subjects' partial reports could not be due to the fact that their attention was distracted because the mere presence of, or a delayed response to, a concurrent tone did not affect partial report (Experiment II). Nor could the reduction be due to some sort of intramodality interference or masking effect because auditorily presented memory items also reduced partial report (Experiment III). Furthermore, a reduction was also observed when the visual effect was held constant (Experiment IV). Experiment IV also ruled out any interpretation in terms of rehearsal or response competition.

We cannot attribute the observed effects to the retention phase of the storage mechanism because there was no Memory Load by ISI interaction effect in any experiment. Could it be that less iconic information would be transferred into short-term memory if the latter were already filled? Our empirical rejoinder to this position is that performance utilizing iconic memory was still reduced when subject had a clear short-term memory store (Experiment IV). Our theoretical rejoinder is that this position relies on an apparently sound assumption that iconic information has to be transferred into the acoustic short-term memory store before any overt response, even a written one, can be made. It follows from this assumption that errors made in partial report should predominantly be acoustic confusion errors and that intertask intrusion errors should be common. Neither of these expectations was met in Experiments I, III, and IV. Also inconsistent with this assumption is the recent observation of Wolford and Hollingsworth (1974) that there were no acoustic confusion errors but there were abundant visual confusion errors in a tachistoscopic whole-report task. That is to say, such a transfer process (of iconic information into short-term memory) need not be an obligatory process, in spite of the fact that an obligatory process has generally been assumed uncritically. 
Could memory load affect the way iconic information was scanned? Let us clarify the term "scan," and let us follow Haber (1973) in identifying iconic information with features like lines, angles, and the like. "Scan," as used in Sperling's (1967) model, refers only to the retrieval (from long-term memory) of pointers to some motor-instruction programs (in long-term memory) on the basis of iconic information available. Iconic information is scanned, in this sense, at a very fast rate (Sperling, 1963). Our data are consistent with the suggestion that memory load might have reduced the scanning rate in the sense that it took longer to retrieve those pointers from long-term memory in the presence of memory load.

One way in which scanning rate might be reduced by memory load could be that contact between iconic memory and long-term memory was achieved via short-term memory. If short-term memory was otherwise engaged, e.g., in rehearsing some items, it could not achieve the contact efficiently. But short-term memory was clear in Experiment IV; hence this alternative can be ruled out. An alternate way in which scanning rate could be reduced might be that there was less iconic information available; consequently, retrieval of pointers was made more difficult. In terms of the pandemonium model (Neisser, 1967), though the number of data or image demons was not reduced by memory load, the number of feature demons subsequently aroused might be reduced by memory load.

In conclusion, contrary to Doost and Turvey's assertion, iconic memory was shown to be subject to interference by a subsidiary task. In this respect, iconic memory is not different from short-term memory; and in this sense, iconic memory is also subject to limitations of the central processor. It was also suggested that memory load might actually reduce the amount of iconic information which could be extracted during stimulus presentation. Current knowledge about iconic memory is obtained from a dedicated-task situation in which the subject could devote himself solely to the iconic memory task. In view of our present findings, we can generalize what we know about the rate of decay of iconic information to a subsidiary task situation. Though iconic memory still holds more information than what was revealed in whole-report performance, its supposedly large capacity was reduced by a light subsidiary task. Evidently, iconic memory is not exempt from the capacity limitations so characteristic of short-term memory.

\section{REFERENCES}

Atkinson, R. C., \& Shiffrin, R. M. Human memory: A proposed system and its control processes, In $K$. W. Spence and J. T. Spence (Eds.), Psychology of leaming and motivation: Advances in research and theory, Vol. 2, New York: Academic Press, 1968.

Broadbent. D. E., \& Heron. A. Effects of a subsidiary task on performance involving immediate memory by younger and older men. British Journal of Psychology, 1962, 53, 189-198.

Doost, R., \& Turvey, M. T. Iconic memory and central processing capacity. Perception \& Psychophysics, 1971, 9, 269-274.

Haber, R. N. How we remember what we see. Scientific American, 1970, 222 (20), 104-112.

Haber, R. N. Visual information storage. In Visual Search; symposium conducted at the spring meeting, 1970 , Committee on Vision, Division of Behavioral Sciences, National Research Council. Washington, National Academy of Science, 1973, pp. 129-150.

Haber, R. N., \& Hershenson, M. The poychology of visual perception. New York: Holt, Rinehart \& Winston, 1973.

Murdock, B. B., Jr. Effects of a subsidiary task on short-term memory. British Joumal of Psychology, 1965, 56, 413-419.

Neisser, U. Cognitive psychology. New York Appleton-Century-Crofts, 1967.

Sperling, G. The information available in brief visual presentations. Psychological Monographs, 1960, 74 (11 Whole No. 498).

Spering, G. Successive approximations to a model for short-term memory. Acta Psychologia, 1967, 27, 285-292. Sperling, G. A model for visual memoxy task. Human Factors, 1963, 5, 19-31.

Turvey, $M$. T. The effects of rehearsing analyzed information upon the retrieval of unanalyzed information. Psychonomic Science, 1966, 6, 365-366.

von Wright, J. $M$. Selection in visual immediate memory. Quarterly Joumal of Experimental Psychology, 1968, 20 62-68.

Wolford, G., \& Hollingsworth, G. Evidence that short-term memory is not the limiting factor in the tachistoscopic full-report procedure. Memory \& Cognition, 1974, 2, 796-800.

(Received March 27, 1975. Revision received April 4, 1975.) 